\title{
An Interview with Eiko Otake
}

\author{
Rosemary Candelario, Texas Woman's University \\ Eiko Otake, Independent Artist
}

Keywords: video, installation, collaboration, photography, A Body in Places

Rosemary Candelario-You and Koma had already been working together for more than ten years when you made your first dance for camera in 1983, Tentacle, with Jeff Bush and Celia Ipiotis. What made you to turn to video at that time?

Eiko Otake-We were approached by Celia and Jeff, who were working as a couple and were eager to develop dance for camera.1 You know, we are practical. They approached us with a vision for a piece, we listened, it was workable, we did it, and we learned something new and important from the process. Then in 1985, the Walker Art Center commissioned us to make Lament and paired us with James Byrne. We were still young at that time and tended to take what came our way. And media people, videographers and the media department of the Walker, were eager to work with us. We always respond to passion.

Through these experiences, I began to learn what it is to edit video, and with the existence of the NEA video dance division, it became possible for us to imagine, apply for, and work on video projects during the time that we didn't have performance engagements.2 You can look at the video as soon as you shoot it. It was very much a cyclic process: you shoot, you look at it, see what works and what does not, discover who likes what for what reason, respond to suggestions, and then shoot again. You know, it was a whole different process from performance, because performance is not repeatable. But you can look at video and make judgments and keep working on it until it feels right. That was a kind of luxury we never had as performing artists. So I was fascinated by this, and by the opportunity to develop our own aesthetic and collaboration strategy. However after feeling some frustration in relying on edits too much, we decided to shoot Husk (1987), in the manner of Tentacle, with no postproduction edit. We realized, "Oh we can do this on our own!" I feel like Husk is very much its own world.

RC - Tell me about how you started making video documentaries of your work.

EO_In 2004 Koma and I were given the Samuel H. Scripps/ADF Award for Lifetime Achievement from American Dance Festival. We were told that we needed to provide a video to be projected at the beginning of the ceremony, and they sent us some examples of other award winners that showed the choreographers' work on stage and 
in the studio, and that included many important people speaking about how wonderful the artists receiving the award are. We wanted to make something different. So we decided to show what we cannot show on the stage and asked our younger son Shin to produce a documentary. The resulting video was My Parents $(2004$,$) a family project. Shin who edited the video and spoke the narration was only$ 17 years old. We looked into old film footage and photos from our youth to give the sense of where we came from and our older son Yuta wrote a script that revealed how we work, think and talk. Even though it was made for the Scripps Award, I continue to show it. The beauty of video work is that you can continue to share it. It introduces us, it offers background information and our artistic concerns.

A year later we created The Making of Cambodian Stories (2005) to publicize the US tour of Cambodian Stories (2006,) which featured nine young Cambodian painters. The video was actively shown on cable TV in places where we would be touring as a way to prepare the audiences by showing the lives of these young artists in Phnom Penh, where the work was created as an inter-disciplinary, inter-generational collaboration. Like My Parents, The Making of Cambodian Stories was a need-based documentary that served its purpose well. Learning from that experience, for our Retrospective Project (2009-2012), the first thing we did was to create a video documentary, The Making of River (2009) with the help of Shoko Letton. River (1995) was a memorable piece of ours that we performed in many rivers. It was not only a physically difficult piece to perform but also to video. We were in dark rivers and were separated from the audience by water. We had little performance footage of adequate quality. So we decided to use day time rehearsal video, which helps viewers to see the very rivers we performed in that become dark masses of water at night. As a result, this video documentary showed something that performances could not. We made each of these documentaries for specific reasons, but after the immediate need is met, we can still show them because the content is solid and real.

RC-Speaking of your Retrospective Project, it was during that time that you began experimenting with new ways of working with performance documentation, producing edits of performance video for use in museum exhibitions, starting with 38 Works by Eiko \& Koma, and continuing into a number of video installations.

EO-Yes, in addition to 38 Works, I produced what I call video "wells" for our exhibitions at the Chicago Museum of Contemporary Art, the New York Public Library for the Performing Arts, and other locations. These freestanding wooden boxes had monitors placed at the bottom of them, each showing a video edited from archival footage. In choosing the footage and editing it, it was important to me that each one have a different length, but that it shouldn't be any longer than necessary. This is my general philosophy about the length of works, whether a live performance or a video. Editing, after all, is a time-based art. But an edited video should also deliver the same sense as the original performance work. At the Chicago MCA exhibit, I saw people 
looking into these video wells and watching the entire video from beginning to end and then going to the next box, and again watching from beginning to the end, I realized given the context and the space, people are willing to watch dance video for its own sake, without knowledge of who I am or what the piece was originally for. That made me even more serious about editing our archival video for use in video installations.

Because Koma never really cared much about video editing, it has become my work. He likes painting, he likes objects and the structures he makes. But I actually like the process of editing. It's like cooking in a way because you work from source material. But I prefer working with another person because it can get too intense doing it alone. I also can't edit with expensive professionals because that would oblige me to make decisions quickly. So I'm very happy to have a young, talented collaborator, Alexis Moh. The thing about the edit is it doesn't matter whose idea it is. Sometimes I am right and sometimes she is right, but we both can see that. Of course there are many different ways to be right. The most important thing is I can take time to see different possibilities, and then choose what feels right.

$\mathrm{RC}$-Our discussion about your process in relation to video and editing seems to me to fundamentally be you wanting people to be able to encounter your work in as many ways as possible. How do the "video postcards" that you started making as part of your 2016 solo Platform series at Danspace, A Body in Places, fit into this?

EO-That was Judy Hussie-Taylor's idea.3 My Platform lasted six weeks and we were doing so many things each day, including site performances around the East Village for small audiences, film screenings, a book club, video installations, and guest performances. Basically, we knew nobody could come to see everything. And all the performances were sold out. So the idea was to quickly make short videos during Platform so people could go to the website and see, oh, Eiko performed in all these different places. We called these video postcards, like if you're traveling and you can't say everything you've been doing, and you write like three lines: "Hi Mom, This is an amazing place. Wish you were here." So that is the idea of the video postcard. During Platform, we put these online every week. This allowed me to disseminate what I did without having a very thorough edit. It was a fast way to share what was happening that particular week: Eiko was here, there, and more. That's very different than the 20minute edited video, A Body in the East Village (2016), which recently screened at the Lincoln Center as part of the Film Society's Shorts Program. That is much more a meditative piece that allows you to imagine you could have been there. Then I have to make decisions about what do I want to show in a way that people can actually get a sense of each performance. A video postcard is not an edited video work that I make as a performer. There's a difference between making a creative archive of a performance work and making video postcard. 
RC - It seems like you hope with these different kinds of videos that your audiences will have different experiences with them. With the video postcards, it seems that you're really trying to extend access, which is a theme throughout your career: How can we make our work accessible to different people?

EO-Yes, the video postcards were very conscious of social media: a way to say hi and quickly see what Eiko is doing (as opposed to watching).

$\mathrm{RC}$ - I want to change topics to talk about your photography project with William Johnston, A Body in Fukushima (2014). Photography has long played an important role in your work, sometimes even being part of the way you develop ideas for pieces, for example with Tree (1988) and the photos you shot with Marcus Leatherdale. How does your collaboration with Johnston compare to your previous photographic work?

EO-It's different! No other photographer has ever offered us, or me, copyright. The work Bill and I do together, we actually co-own it. Usually photographers, no matter how great of people they are-and many of them are wonderful friends-they own it. They come, they shoot. It's my costumes, my set, my dance, my thoughts in my body but it's their work. With Bill, not only did I not pay him, but I actually co-own the work. Dancing, moving, that's totally my thing. I decided to go to Fukushima, then we both began choosing places. But until recently he has never said to me, "How about this?" And I'd almost never suggest to him how to shoot. During the shooting process he does whatever he wants, and I do whatever I want. Afterwards, we select photos together. We have a 1-5 scale: 1 is "not over my dead body," 5 is "you really have to include this." But 2, 3, 4 we can negotiate. What he chooses looks good from a photographic point of view. Me, as a dancer and choreographer, my approach is to look at the whole picture, myself, and my relationship to the whole picture. If something is 2 for him and I understand why, I would not use it in an exhibition, but I can use his 2 in my video work-even if it's blurred, or if it's not quite right. Such selections sometimes interest me as a choreographer. In creating a video from photographs, I do not want to line up just great photos. We need different textures and dynamics to make a video as an art work. We are both very concerned about the environment. He is a scholar, he is a wonderful photographer. I am not a scholar, I am a dancer, a performer. So we have different places that we operate from. I learn a lot from him through the negotiation. We understand the other person's point of view. And that has been the process. Then I make videos from our photos and I often design our exhibitions. He's a full-time professor, so I have a little more time to work on these things and I have more communication with my producers. He sometimes has suggestions, however, and often writes the exhibition text. Bill is good at this of course, so we have different strengths.

In May 2017, we had an exhibition at Topaz Arts, a dance studio and small gallery in Queens. I gave a 2-hour movement workshop followed by an opening reception for 
the exhibition, during which I performed. In the exhibition, half of the photographs were from Fukushima and the other half were from Indian Point, the nuclear power plant just up the Hudson River from New York City. By hanging the photographs on adjacent walls, we were making a connection between the two nuclear plants: what happened to one could happen to the other. In the next room we displayed video of the photographs. I began my performance naked in front of the video, as if I were emerging from the video where my naked body was breathing in Fukushima. I then put on my costume and danced in the gallery in front of my photos. My concern there was how to present my body in a much more raw state. It really gives me a different idea of how to perform because I didn't want to look like just another Eiko though it is clearly the same person as in the photographs; I want this performing body to be more chaotic than the one in the photos. A performing body is of course more than selected images. I took the audience outside into the street and I stopped some taxis because I was literally in the middle of the street performing. Then I took the audience around the corner and ended in front of an electric power structure.

So what I am trying to say here is that this collaboration is giving me a different process to work from. I performed at Indian Point and in Fukushima. Bill shot photos. We selected photos together. The video I made of the Fukushima photos is projected in one gallery, and the photos from Indian Point and Fukushima were exhibited in the adjacent gallery. And then by the time I'm performing in front of his photos I don't want to just be a self-absorbed performer dancing in the midst of my own photos. So I try to make my body a different kind of a body, but still somehow connected. It's been a challenging journey for me because as a solo performer I don't have many different layers. So his photos and my media work and the way I construct the place of the exhibition give me different layers to work with. There is a very clear intention of addressing environmental issues, too.

RC-With your solo project, $A$ Body in Places, you've been directly addressing specific issues like nuclear power and the environment in connection with specific places. And even though you and Koma often performed very close to your audience in your installation work, the way you perform as a solo artist involves a very direct address with the audience. How do you think that developed? Are both of those things coming out of a desire to address issues more directly than you did as Eiko \& Koma, or is it you as a solo performer needing to use your body differently to engage the audience and space differently?

EO-It's a combination. It has a lot to do with the fact that as a solo artist I arrive to a new community alone. If I am touring with Koma, they assume we are having dinner together or that we need time together to plan. But if I am alone, I am more available to the community and I'm working closely with other people. So it just means there is more communication happening in many different ways: talking before the performance, and communicating during the performance with the individual 
audience member. And also remember I'm not performing under theater lights. If I look at one particular person, everybody knows I am looking at that person. And that person knows that everybody is watching. And everybody knows it could have potentially been another person. Or everybody can imagine, "that could have been me." So the evenness of the gaze is totally broken. That's a different kind of excitement between a performer and viewers.

Fukushima is like an exemplary disclaimer-everything that wasn't supposed to happen happened. Bringing in Fukushima also gives a different engagement for people to look at, the way my body is seeing and relating to something. It's a complex relation that gives a certain weight, a certain flavor. The direction to Fukushima is different than the direction to Ireland. I like it in a way that it makes it feel not equal. It's absolutely urgent to me that there has to be some kind of danger in my solo performance, there has to be some kind of effort, some kind of crevasse that I could fall into. I'm thinking those things as I'm performing. Under my antics there could be some kind of a dangerous crevasse.

$\mathrm{RC}$ - It's interesting how audiences have been able to witness through your video documentation of all these different places over the last three years, starting with Fukushima but then Philadelphia, and Hong Kong at a place where there were major protests, and Wall Street, but then also a library, a bookstore, a community center....The accumulation of these very charged places and these very everyday places asks people to question the relationship between their daily lives-the shop they go to every day, the street they go down...

EO-These also give a different function to the performer's body. It's almost like my body becomes that of an ancient traveling performer who used to carry news between different countries, before TV, before telegrams. The performers knew the different communities' news and carried it from one place to another. Being a performer, I think our bodies are open to absorb things. My body has been to Hong Kong so I carry that sense of weight of a place, I carry the decisions I made there about selecting a site and selecting certain moves. My body carries Hong Kong, carries Chile, carries the library, carries the station. I've also been thinking a lot about how some of the people who saw me perform in Philadelphia or Hong Kong could now be dead, the way that my friend died right after seeing me in Chile. My body is almost like a deposit of peoples' gazes. And I like to imagine that certain people, not everyone, feel like "oh my god, this body has been going to so many places. Oh, my body has also gone to these places." So I look at my body and feel my body differently.

In this work, my presenters have become very much collaborators, more so in this project than any other project I have ever done except perhaps River. So that's great. I feel like it's not my own creation. I'm not really that interested in myself. But I'm 
interested in my body becoming a kind of fieldwork that other people have also worked on.

\section{Biographies}

Rosemary Candelario writes about dance and popular culture through the lens of gender, race, and ethnicity. Whether she is addressing the Japanese avant-garde dance, butoh, Asian American dance, vampires, cyborgs, or mass protests, an attention to the political efficacy of moving bodies pervades her work. Rosemary's book, Flowers Cracking Concrete: Eiko \& Koma's Asian/American Choreographies was published by Wesleyan University Press in 2016. She has also published in the Journal of Theatre, Dance and Performance Training, The Scholar and Feminist Online, The International Journal of Screendance, Asian Theatre Journal, and The Oxford Handbook of Dance and the Popular Screen, among others. Her choreography has been produced across the United States, and as a dancer she has performed across the United States and in Brazil, Canada, Germany, and South Africa. Rosemary earned a PhD in Culture and Performance from UCLA and is Assistant Professor of Dance at Texas Woman's University.

\section{Email: RCandelario@twu.edu}

Web: http://www.rosemarycandelario.net

Born and raised in Japan, Eiko Otake is a New York-based movement artist, performer, and choreographer who for more than 40 years worked as Eiko \& Koma. Since 2014, she has directed and performed a solo project, A Body in Places, in which she collaborates with photographer and historian William Johnston to create and present a series of exhibitions showing her dancing in irradiated Fukushima and elsewhere. Using archival footage and photographs of her performances, Eiko has also created media works and video installations that have been shown in galleries and at film festivals. As visiting artist at Wesleyan University since 2006, Eiko has taught interdisciplinary college courses on the Atomic Bomb and other environmental disasters using movement as a means of inquiry. She also teaches regularly at Colorado College and NYU.

Email: eikootake@gmail.com

Web: http://www.eikoandkoma.org 


\section{Notes}

1 Celia Ipiotis and Jeff Bush, through their organization ARC Videodance, were the creators and producers of the long-running PBS show, Eye on Dance, in addition to making a number of videodances (https://vimeo.com/channels/arcvideodance). In addition to Tentacle, Eiko \& Koma made Wallow (1984) and Bone Dream (1985) with Bush.

2 For more on Eiko's work behind the camera and in the editing room, see Eiko Otake, "A Dancer Behind the Lens." 3 Judy Hussie-Taylor is Executive Director and Chief Curator of Danspace.

\section{References}

38 Works by Eiko \& Koma. Dir. Eiko and Koma Otake. Ed. Eiko Otake with Tara Kelton and Shoko Letton. USA, 2009-2012.

A Body in Fukushima. Chor. and perf. Eiko Otake. Photo. William Johnston. Site-based performance and photography. 2014.

A Body in Places. Chor. and perf. Eiko Otake. Site-based performance. 2014-2017.

A Body in the East Village. Dir., chor., and perf. Eiko Otake. USA, 2016. http://eikoandkoma.org/ABodyinEastVillage

Bone Dream. Dir. Eiko and Koma Otake with Jeff Bush and Celia Ipiotis. Prod. ARC Videodance. USA, 1985. http://eikoandkoma.org/index.php?p=ek\&id=1879

Cambodian Stories. Chor. Eiko and Koma Otake with Reyum Painting Collective. Performance. 2006.

Dancing in Water: The Making of River. Dir. Eiko and Koma Otake. 2009. http://eikoandkoma.org/dancinginwater

Husk. Dir. Eiko and Koma Otake. USA, 1987. http://eikoandkoma.org/videoofhusk

The Making of Cambodian Stories. Dir. Eiko and Koma Otake. USA, 2006. http://eikoandkoma.org/themakingofcambodianstories

My Parents. Dir. Eiko, Koma, and Shin Otake. USA, 2004. http://eikoandkoma.org/myparent 
Otake, Eiko. "A Dancer Behind the Lens." In Judy Mitoma (Ed.) Envisioning Dance on Film and Video. New York: Routledge, 2002. 82-88.

River. Chor. and perf. Eiko and Koma Otake. Site-based performance. 1995.

Tentacle. Dir. Eiko and Koma Otake with Jeff Bush and Celia Ipiotis. Prod. ARC Videodance. USA, 1983. http://eikoandkoma.org/index.php? $\mathrm{p}=\mathrm{ek} \& \mathrm{id}=1880$

Tree. Chor. and perf. Eiko and Koma Otake.1988.

Wallow. Dir. Eiko and Koma Otake with Jeff Bush. Prod. ARC Videodance. USA, 1984. 